\title{
Fichte y el ejercicio de la Ilustración en Berlín
}

\section{Marco Rampazzo Bazzan}

\section{(2) OpenEdition}

\section{Journals}

\section{Edición electrónica}

URL: http://journals.openedition.org/ref/981

DOI: $10.4000 /$ ref.981

ISSN: 2258-014X

\section{Editor}

EuroPhilosophie Editions

Referencia electrónica

Marco Rampazzo Bazzan, «Fichte y el ejercicio de la llustración en Berlín», Revista de Estud(i)os sobre Fichte [En línea], 18 | 2019, Publicado el 01 junio 2019, consultado el 26 enero 2021. URL: http:// journals.openedition.org/ref/981 ; DOI: https://doi.org/10.4000/ref.981

Este documento fue generado automáticamente el 26 enero 2021

(c) EuroPhilosophie 


\title{
Fichte y el ejercicio de la Ilustración en Berlín
}

\author{
Marco Rampazzo Bazzan
}

\section{NOTA DEL AUTOR}

Este articulo es parte de mis investigaciones realizadas en la PUCPR-Curitiba durante la beca post-doctoral que me otorgó CAPES (programa CAPES-PNPD)

\section{Introducción}

En la huella del idealismo transcendental kantiano, la Doctrina de la ciencia (=WL) ambiciona realizar una reflexión que critique radicalmente las verdades establecidas (FSW IV, 374). Radicalizando la perspectiva de Kant, Fichte pretende cuestionar genéticamente las formas bajo las cuales estas verdades establecidas se presentan en la consciencia ${ }^{1}$. Como veremos, no se trata de eliminar estas 'verdades' denunciándolas meramente como ilusorias - pues, ilusoria es apenas su pretensión de ser verdad - sino de entenderlas en su necesidad en la medida en que representan momentos ineluctables de un proceso de esclarecimiento del saber ${ }^{2}$. De hecho, ellas constituyen la condición factual para el desenvolvimiento de la filosofía como $\mathrm{WL}^{3}$, ya que definen su ineludible y contingente punto de partida, o sea el objeto de su aplicación específica ${ }^{4}$.

Por otro lado, la relación continua y variable entre lo que se cree verdadero (fe) y lo que se comprende (entendimiento) como tal es también, para Fichte, el núcleo de la historia humana ( $F S W V I, 495-496)$. Esta relación define el horizonte problemático dentro del cual el filósofo concibe la historia y el destino del hombre como manifestación y desarrollo de la libertad. Bajo este aspecto cabe destacar cómo su concepción de la historia representa básicamente una reformulación del proceso de la Ilustración en la huella de Kant. Para entenderlo destacaremos la correspondencia entre las nociones de fe, utilizada en la Doctrina del Estado de 1813, y de símbolo (o profesión de fe), utilizada 
en el Sistema de ética de 1798 y en el curso de Doctrina Ética de 1812. Con lo cual, veremos cómo Fichte concibe la historia a partir del papel que él atribuye a los eruditos en su teoría pedagógica, desarrollando aquí también algunas tesis que Kant había enunciado tanto en su "Respuesta a la pregunta: ¿Qué es ilustración?" como en la Religión dentro los límites de la mera razón ${ }^{5}$.

Para comprender la profundidad de la influencia de la concepción kantiana de la Aufklärung en la definición del ejercicio concreto del filosofar in actu ${ }^{6}$ por Fichte, analizaremos, por ende, los rasgos de esta práctica a partir de dos "dificultades capitales" que, según él, cabe enfrentar necesariamente en el desenvolvimiento efectivo de la WL. El filósofo menciona estas 'dificultades' en el prólogo de la exposición de 1811 justo antes de evocar la exhortación horaciana, que Kant resignifica en 1784 como divisa de la Ilustración. La primera dificultad es la manera de entender el filosofar tal como una 'clasificación de las filosofías' (DC 1811, 69). La segunda es la acción del 'pensamiento dogmático' (dogmatischer Sinn). Así, a partir de la manera en la cual él encara las dificultades mencionadas, intentaremos evidenciar la disposición ética (Gesinnung) que la WL - o sea la Sabiduría (Weisheit) - pretende forjar como práctica de la Ilustración. Pues el ejercicio del pensamiento crítico forja una actitud ética (una manera de ser o actuar) por medio de una nueva "manera de ver" (SL 1812, 384), justamente aquella anunciada en las lecciones introductorias que ahora examinaremos en la versión de 1811.

\section{La actitud polémica de la WL}

Antes de todo, cabe esclarecer lo que Fichte elabora bajo WL. En 1811 él la presenta tal como un "análisis de la conciencia" (DC 1811, 55). En cuanto tal la WL se produce mediante una reflexión sobre lo que se presenta como saber en la consciencia natural. Esta reflexión pretende estudiar y reconstruir los "miembros intermedios desconocidos, invisibles para el sentido ordinario" ( $D C$ 1811, 55) que producen los contenidos concretos de la conciencia. Fichte define esta reconstrucción como movimiento 'genético' (en contraposición a 'factico') ${ }^{7}$. Con lo cual practicar la WL exige cuestionar lo que se reconoce usualmente como verdadero y que se acepta factualmente como tal a partir de un principio que no habría sido 'genetizado' (FSW IV, 379). Bajo esta perspectiva, la WL define un pensamiento que no acepta nada como verdadero sin justificación racional. 0 sea, ella no puede admitir algo como verdadero simplemente porque así lo sanciona una autoridad científica, religiosa o política. Por esta razón se opone a toda forma de autoridad en el ámbito del saber. Así, para Fichte, "el único modo de pensar según y por el cual es posible una WL" es "mediante oposición" (DC 1811, 55). En la introducción a la Doctrina del Estado él presenta esta oposición (entre "cosas" e "imágenes") a partir de una manera diferente de ver el Ser (FWS IV, 373).

La resurgencia del lema 'sapere aude' en la clase del 5 de febrero de 1811, nos permite investigar esta oposición desde el punto de vista de la exposición efectiva de la WL en el marco de la definición kantiana de la Ilustración. Esta clase concluye el prólogo o prolegómenos (termino que Fichte utiliza en las exposiciones de 1804 e 1807), o sea el metadiscurso con el cual Fichte abre su exposición ${ }^{8}$. Este discurso preliminar se plantea la tarea de orientar de forma 'performativa' ${ }^{9}$ a la audiencia, para que realice sin preconceptos su investigación sobre el saber. Fichte se apropia de la exhortación 
horaciana para que sus oyentes se predispongan e inicien a practicar el tipo de ejercicio que define la WL como cumplimento de la perspectiva transcendental abierta por Kant. Con otras palabras, apropiándose el 'Sapere aude', Fichte resume la exhortación que él mismo está formulando a su audiencia.

Pero aquí luchamos contra la autoridad. Eso lo han dicho también hombres famosos y reconocidos. Yo mismo no contrapongo a esto autoridad alguna, sino sólo la propia visión [eigne Sicht]. Ahora, mediante esta propia visión de ustedes, si ustedes están dispuestos, si sapere audetis, quiero mostrarles en breve lo que todos los hombres famosos y reconocidos en el mundo, sin excepción de uno solo, son en el campo de la filosofía, y el talento y la agudeza que nuestra época científica tiene que aplicar y emplear (DS 1811, 70).

Esta observación precede la verdadera introducción a la WL, que Fichte desarrolla diferenciando su planteamiento de las filosofías de Schelling y Spinoza. Fichte convoca a los dos autores justamente como 'autoridades filosóficas' frente de las cuales su discurso debe tomar posición oponiéndose a ellas ${ }^{10}$. Con lo cual, según Fichte, a la WL pertenece constitutivamente una actitud polémica. $O$ sea, su construcción se forja desmarcándose de las posiciones que poseen autoridad en el momento de su exposición efectiva (y que, por eso, definen las verdades establecidas en el plano científico). Según Fichte, "quien actúa por una autoridad, actúa necesariamente sin consciencia moral", porque carece de 'certeza' (SisEt, 220). Pues "el sentimiento de la certeza nace por la convergencia de un acto de la facultad de juzgar con el impulso moral" (SisEt, 220). Ahora bien, en Fichte, la exhortación 'sapere aude' designa precisamente la ambición de realizar este tipo de 'convergencia' en la cual consiste la anhelada y siempre problemática unión de saber y acción.

Para Fichte, se puede contrastar eficazmente la fuerza de toda autoridad si sus dictámenes se historizan en presente. Según explica en la Doctrina del Estado, eso significa comprender en qué medida "la propia época es determinada por el intelecto y en qué medida por la fe, y en qué punto los dos principios están en conflicto" (FSW IV, 493-494). Para aclarar este aspecto cabe reanudar esta consideración con el uso de símbolo en el Sistema de Ética destacando su ascendencia kantiana. Fichte define "su símbolo" como el fundamento de la fe de una comunidad particular, o sea aquello sobre lo cual todos están de acuerdo (SisEt, 269). Esta idea es confirmada en el curso de Doctrina ética de 1812, en el cual Fichte designa con 'símbolo' "el consenso sobre la visión" que funda una comunidad ${ }^{11}$.

Con lo cual Fichte considera el símbolo como el "fundamento de la enseñanza" (SisEt, 276). Para él su contenido concreto no es dogmático, sino "modificable" o "perfectible" (SL 1812, 388). Su modificación 'adecuada' - o sea en vistas al progreso de la Ilustración define, por lo tanto, la tarea que se plantea para los eruditos. En breve, el símbolo constituye la convicción compartida por una comunidad de escucha particular. Esta convicción compartida determina el punto de partida para el discurso que los 'verdaderos eruditos' (tal cual Fichte pretende ser) articulan sobre un determinado asunto. En su caso específico, la tarea de Fichte como profesor es iniciar su discurso a partir de las posiciones de hombres "reconocidos y famosos" de su época sobre la filosofía. Pues son justamente esas opiniones que forjan las verdades establecidas de su tiempo.

De esta forma resulta suficientemente claro que la filosofía como WL se produce por una diferenciación frente a un saber determinado. Este saber particular no es otra cosa que el objeto de la conciencia natural o del sentido común. La WL intenta cuestionar 
este saber particular a partir de su principio (reconstruyendo genéticamente su formación como objeto de la conciencia). La dificultad principal para la comprensión de la WL consistiría justamente en el hecho que ella procura "distinguir lo que la conciencia común no distingue" (DC 1811, 63). Pues eso nos aclara cómo el filósofo pretende construir la WL a partir de lo que él considera como fundamento de la opinión dominante sobre un determinado tema por parte de la audiencia particular. Ese fundamento seria justamente la imagen de lo que esta audiencia o comunidad de escucha cree verdadero sobre la filosofía, el saber, una ciencia particular, un posicionamiento político, o sea todo objeto sobre el cual se aplica el pensamiento o al cual se dirige (o pretende dirigirse) la reflexión.

Como hemos mencionado, esta imagen del objeto de fe corresponde a la definición de 'símbolo' presente en el Sistema de ética. Fichte analiza la noción de 'símbolo' en el párrafo 18 cuyo objeto son "las condiciones de la yoidad en su relación con el impulso a la autonomía absoluta". En esta sección Fichte identifica el destino (Bestimmung) del hombre con el perfeccionamiento moral. El uso que hace de la noción de símbolo se inspira en el de Kant en la Religión dentro de los limites de la mera razón. A este texto Fichte se refiere explícitamente para introducir el asunto de la existencia del mal radical (SisEt, 239). Se trata de un texto cuya lectura lo había marcado profundamente como prueba una carta que escribe a Kant en 1792. Pues en esta carta Fichte sustenta que el ensayo sobre la religión lo habría influenciado en la escritura de las Contribuciones para rectificar el juicio del público alemán sobre la Revolución francesa (GA III/1, 431) ${ }^{12}$.

A partir de estas consideraciones podemos individuar en la "Observación general", que encierra la Religión dentro los limites de a mera razón, la fuente primaria de inspiración para la concepción de la historia que Fichte articula en la Doctrina del Estado. Como mencionado, en las conferencias de 1813 Fichte sostiene que el núcleo de la historia humana es el conflicto entre fe (Glauben) y entendimiento (Verstand). Ahora bien, la primera manifestación del Glauben es la 'fe en los milagros' (FSW IV, 466). La 'fe en los milagros' caracteriza, desde luego, la época del obscurantismo, en la cual se concibe la historia como 'providencia' o 'gobierno divino del mundo'. Fichte trata del milagro como objeto de la opinión corriente, o sea lo que una determinada comunidad considera (o cree) verdadero (en el ámbito suprasensible). Pues la opinión corriente consideraría el milagro como el efecto de la decisión de un "Dios inteligible, sabio y moral" (FWS IV 466). Al mismo tiempo el milagro se presenta como un "acontecimiento natural', o sea como algo que se produce en el orden natural y que, no obstante, no se explica a partir del determinismo mecanicista. Con lo cual, el milagro representa el primer intento de explicar un acontecimiento que no puede reconducirse a las leyes de la naturaleza. En esta medida, eso se puede percibir tal como la primera percepción de la causalidad del mundo suprasensible. Es por este camino que un cuestionamiento sobre el milagro puede abrir a la comprensión del mundo moral gobernado por la libertad. De hecho, lo esencial para todo símbolo, del cual el milagro sería la primera percepción histórica, es la proposición: "hay en general algo suprasensible y elevado por encima de toda naturaleza" (SisEt, 276).

Ahora bien, la percepción de un principio suprasensible (o sea que no es sujeto a las leyes de la naturaleza) pone a disposición el material de la historia (fundamentado el espacio de pensabilidad para los efectos de la libertad). Este tipo de percepción constituye el objeto de fe, del cual el filósofo habla en 1813. Se trata de una convicción, es el acto de creer en algo que, en este caso, no tiene ningún sustento particular 
racional. En este punto no es difícil reconducir otra vez su argumentación a la Religión dentro los límites de la mera razón. En este texto Kant consagra a este asunto su segunda "Observación general". Según Kant, con la fundación de una religión moral, "todos los milagros que la historia enlaza con su introducción han de hacer finalmente superflua la creencia en milagros en general" (AA VI, 84). Se puede entonces afirmar que Fichte desenvuelve su argumentación a partir de los tres modos de 'fe ilusoria' que tiene lugar en la trasgresión, para nosotros, de los límites de nuestra razón respecto a lo sobrenatural. En el caso mencionado resulta decisivo el primero de estos modos, o sea "la creencia de que se conoce por experiencia algo que, sin embargo, nos es imposible aceptar como aconteciendo según leyes objetivas (la creencia en milagros)" (AA VI, 194).

En 1813 Fichte insiste en el hecho de que, aunque sea inadecuada, la fe en los milagros representa una primera percepción consciente de lo suprasensible. Según el sentido aclarado antes, se trataría de la primera manifestación del símbolo como signo de la existencia de algo sobrenatural, o sea que no es sujeto a las leyes (mecánicas) de la naturaleza sensible, lo que corresponde, por lo tanto, a un producto de la libertad. Así, el verdadero objeto de la historia humana es el desenvolvimiento de la libertad moral. Ese desenvolvimiento indica al hombre su destino en el perfeccionamiento moral. Aquí está la razón por la cual no podemos entender el 'plano universal' (Weltplan) como algo definido en el marco de una providencia predeterminada, sino como una tarea cuyo cumplimiento depende del reconocimiento por parte de los hombres de su naturaleza moral en el ámbito del género humano. También a esta altura podemos observar que Fichte desenvuelve una tesis de la Religión dentro los límites de la mera razón. Según Kant, la formación moral del hombre no tiene que comenzar por el mejoramiento de las costumbres, "sino por la conversión del modo de pensar" (AA VI, 48). Bajo esta perspectiva podemos entender como objetivo de la WL lo de realizar esta 'conversión' forjando una 'visión propia'.

Es con este objetivo que Fichte se apropia la divisa de la Ilustración. Pues Kant había utilizado la noción de 'símbolo' (Symbol) - traducida a veces por "credo asumido" también en su Contestación a la pregunta: ¿Qué es ilustración? Para el filósofo de Königsberg, la época de ilustración coincidiría con el siglo de Federico porque el monarca permite:

a venerables clérigos que, como personas doctas, expongan libre y públicamente al examen del mundo unos juicios y evidencias que \se desvían aquí o allá del credo asumido por ellos sin menoscabar los deberes de su cargo; tanto más aquel otro que no se halle coartado por obligación profesional alguna. los eclesiásticos (AA VIII, $40-41)^{13}$.

Según Kant, el símbolo como creencia no es algo inmutable en su forma. Pues considerarlo como inmutable negaría la posibilidad de pensar la Ilustración como proceso. Es por lo tanto "modificable" exactamente como sustenta Fichte en 1798. Ahora podemos entender aún mejor cómo la concepción fichteana del núcleo de la historia humana tal como conflicto entre fe y entendimiento traduzca finalmente la dialéctica entre símbolo (credo) e ilustración definida por Kant en 1784 como motor del proceso de Aufklärung. En la Doctrina del Estado la fe representa el termino a quo para el desenvolvimiento de la inteligencia (Verstand) (FWS IV, 495). La fe define los contenidos de la historia, materiales o contingentes, que el entendimiento debe aclarar (es decir 'genetizar' en el sentido explicado anteriormente). 


\section{Visión propia contra autoridad}

En el paso de la WL de 1811, en el cual evoca el lema 'sapere audere' Fichte opone la 'visión propia' a la autoridad. Esta 'visión propria' corresponde a la actividad del 'entendimiento' (Verstand) descrita en la Doctrina del Estado. El entendimiento comprende lo que es originario que no encuentra, sin embargo, en si mismo, sino en la fe. Pues el entendimiento no crea nada, sino comprende lo que se presenta en la conciencia (FWS IV, 494). La WL se plantea justamente la tarea de comprender lo que es originario y los prolegómenos sirven justamente para definir (tomar conciencia de) este objetivo. En 1811 Fichte empieza su exposición con las palabras siguientes:

Doctrina de la ciencia. Dice el nombre. Hasta aquí [se explicó en las exposiciones] anteriores. Aquí solo [buscamos] en breve un concepto conductor fijo, que permanezca. [No doy] ninguna fórmula, sino que, con arreglo a mi presente descripción, ustedes deben configurarlo y fijarlo en sí mismos (DC 1811, p. 55).

Fichte está convencido de que aprender y filosofar implican una apropiación creadora, y no mecánica del saber. Como relata August Twesten, uno de sus estudiantes más cercanos en Berlín, Fichte le pedía a su público no tomar ningún apunte durante sus clases, para no verse negado el acceso a la inteligencia de la WL. En opinión del filósofo, al hacer sus anotaciones sus alumnos perderían la fuerza del discurso para quedarse simplemente con la letra ("muerta") ${ }^{14}$. La metáfora que Fichte utiliza es justamente que cada oyente forme una 'visión propia'. El primer paso para formar esta nueva manera de ver debe producirse por medio de una diferenciación frente a la manera corriente de ver las cosas, eso es la 'conciencia natural'. O sea, la conciencia natural no describe apenas creencias ingenuas del sentido común, sino también lo que una cierta comunidad (o público) considera como justo y verdadero, eso es su símbolo. Y este símbolo incluye también las proposiciones de las ciencias. Brevemente, la manera habitual de ver corresponde a la visión dominante en una cierta época por parte de cierta comunidad.

Cabe ahora destacar cómo Fichte habla de la Ilustración en sus escritos. Como lo destaca Ives Radrizzani, la visión binaria de la dialéctica de la ilustración de Fichte en Jena se complica a partir de la 'disputa del ateísmo'. Esta complicación deriva del hecho de que Fichte forja e introduce una categoría intermedia, es decir: "los partisanos de la obscuridad que se consideran ellos mismos como partisanos de la luz" ${ }^{15}$. Fichte llama "falsos hombres de la ilustración" a aquellos hombres de cultura o filósofos de su época - bajo los cuales hay que entender "los hombres celebres y estimados" mencionados antes - que, a pesar de criticar (con palabras) el obscurantismo pasado, obrarían en favor del obscurantismo o del status quo con el objetivo de desempeñar el papel de tutores del pueblo.

Sobre esa presumida incoherencia entre palabras y acciones se basa la convicción del Fichte, según la cual la mayoría de sus colegas no cumplía con la tarea de los verdaderos eruditos. Cabe entender esta distinción entre verdaderos y falsos iluministas a partir de los "verdaderos eruditos", de los cuales habla Rousseau en el primero Discurso ${ }^{16}$. En 1798 Fichte sustenta que los verdaderos eruditos son "los depositarios, algo así como el archivo de la cultura de la época" y que su tarea consiste en "hacer progresar ese conocimiento", es decir, "corregir el conocimiento actual" mediante "la rectificación" y "una ampliación del conocimiento". La esfera de la acción de los eruditos es "el público docto; a partir de él, por el camino conocido, llegan los resultados de sus investigaciones a toda la comunidad" (SisEt, 346). Es un verdadero 
erudito apenas quien cumpla efectivamente con esta tarea. En consecuencia, quien no cumpla con esa tarea actuaría contra el progreso de la Ilustración. Es el caso por ejemplo de:

Hélvetius y otros los cuales decían: es un hecho que el hombre lo hace todo por egoísmo, y no hay en modo alguno otro fundamento para la acción en su naturaleza; ésta es su determinación, él no puede ser de otra manera y no debe serlo; y quien quiera ser mejor ahí, es un loco y un visionario que desconoce los límites de su naturaleza. Por este razonamiento, a aquel que se lo cree considerando el asunto de manera natural- se le quitan las ganas y se le hace imposible toda aspiración hacia algo superior (SisEt, 227-228)

En su polémica de 1800 Fichte se dirige, en general, contra todo lo que hace autoridad, y en particular al órgano de la Aufklärung berlinés ${ }^{17}$. El objetivo de esta crítica es la Allgemeine Deutsche Bibliothek porque el público tiende a identificar la Ilustración con las posiciones ahí publicadas ${ }^{18}$. En los Caracteres de la edad contemporánea Fichte sustenta que, si se considera la WL como algo paradójico es básicamente porque se contrapone y rechaza las doctrinas dominantes de su época. Jugando con los prefijos de su lengua Fichte nombra esas doctrinas como Ausklärung (GA I,8, 223), o sea, oscurecimiento. Distinguiendo entre verdaderos y falsos hombres de la Ilustración, Fichte articula entonces diferentes interpretaciones de la Aufklärung, correspondientes a unas posiciones de autores "célebres" o "estimados" de su época. Intenta salvar el núcleo positivo contenido en la definición kantiana, desmarcándolo de las posiciones que se revindican (formalmente) como 'ilustradas' 19 .

En el Sistema de ética Fichte define el 'público docto' como "un fórum de una conciencia colectiva frente el cual se puede pensar e investigar todo lo posible con absoluta e ilimitada libertad" (SisEt, 278). El fin de esta sociedad particular sería de investigar más allá de los límites fijados por "las cadenas del símbolo eclesiástico" es decir de la profesión de fe de una comunidad particular, ósea la imagen concreta que ha asumido en general lo suprasensible, y por los "conceptos jurídicos sancionados por el Estado" (SisEt, 278).

El docto se distingue del no-docto de la siguiente manera: este último cree, en efecto, también haberse convencido por medio de su propia reflexión, y la tiene; pero quien ve más lejos que él, descubre que su sistema sobre el Estado y la iglesia es el resultado de las opiniones más corrientes de su época (SisEt, 279).

Ahora según los deberes particulares del sabio que Fichte presenta en la parte final del Sistema de ética para cumplir con su función social, el docto tiene que disponer la capacidad de comunicar (Mitteilungsfertigkeit) y de recibir (Empfänglichkeit). Estas capacidades le permiten actuar sobre aquel influjo (por medio del intercambio intersubjetivo) y sobre la propagación del saber (como Ilustración ${ }^{20}$ ) en la sociedad, es decir sobre la formación y la transformación de la opinión que funda el consenso en favor del orden constituido, modelado por las autoridades espirituales y políticas. Al mismo tiempo - y este aspecto marca la diferencia fundamental frente la definición de las 'fabricas del consenso' del despotismo perfecto - el proceso de formación de la convicción y de la opinión corriente "es posible sólo por el medio de una "comunicación con los demás", un ejercicio de la duda, una confrontación abierta y el respeto tanto del "símbolo como base de su enseñanza" (la opinión corriente y las acostumbres, objeto del cuarto tipo de ley del cual Rousseau habla en el Contrato social $\left.{ }^{21}\right)$. En este sentido el sabio tiene que conocer el dominio de la ciencia, de todo lo que se realizó en el pasado, y también las disposiciones vigentes con respecto a la fe y a la legislación en la medida en la que esas determinan "concordancia de mi experiencia con la experiencia de otros" (SisEt, 276). La finalidad a la cual el docto debe aspirar y a la 
cual debe educar los otros es que piensen por si mismos (Selbstdenken) sin seguir una guía o autoridad externa, forjando una convicción interior.

Lo que nos interesa ahora destacar es cómo esta articulación permita entender la estructura expositiva de la WL, revelándonos su anclaje dialéctico en el presente. Según Fichte lo que marca la diferencia especifica de la WL respecto de la filosofía de Kant se produce en el abandono de la comprensión factual del 'yo pienso' bajo la cual caen también los así denominados kantianos bajo la pulsión de la consciencia natural (FDN, 106). Cabe entender la diferencia entre saber y creencia o fe que marca la línea de confrontación básica a partir de la cual Fichte elabora las exposiciones de la WL a partir del Destino del hombre y que termina con la confrontación entre "mundo antiguo" y "mundo nuevo" en la Doctrina del Estado. En las exposiciones que siguen a la disputa sobre el ateísmo encontramos de hecho la deconstrucción critica de las tesis y figuras que él había forjado en las primeras versiones bajo la crítica del 'concepto muerto', es el caso de la 'Yoidad' o del 'Yo' que Fichte ahora analiza como malentendidos (y como conceptos falsos de la WL).

En Berlín Fichte se enfrenta con los efectos de sus exposiciones anteriores sobre la formación de la idea, del prejuicio que este publico particular puede tener sobre la WL, es decir de lo que se entiende corrientemente por ella. En este sentido los prejuicios sobre la WL, sus (mal)entendidos o su letra tienen que ser superados gracias a su desarrollo en el presente por medio de su apropiación critica, mediante un movimiento de deconstrucción y de reconstrucción de sus figuras. Si formalizamos lo que explica Fichte en estas clases, la filosofía sería una reflexión sobre lo que está reconocido como verdad en el plano científico, religioso y político en una determinada época. Su desenvolvimiento efectivo ambiciona formar una comunidad de intenciones, determinada como embrión de un público verdaderamente erudito.

Así, en su exposición efectiva, la WL se produce a partir de esas posiciones que hacen "autoridad". Esas posiciones entran en el discurso de la WL como objeto de su reflexión junto a los malentendidos de estas (es decir la WL como objeto de su recepción por un individuo $\mathrm{x}$ ). Sobre este punto podemos recordar las palabras de Fichte en la introducción general a la Doctrina del Estado.

Habría malentendidos a) si se considerase la doctrina de la ciencia como el nombre de mis escritos, conferencias etc. para denotar algo de dado históricamente, como teoría de la facultad de la representación, critica de la razón. Pues no, ella [la doctrina de la ciencia] es lo que afecta a todo el mundo y lo que todos han buscado desde que hay un pensamiento claro sobre un cierto punto. Se me podría contestar que mis escritos y conferencias no son la doctrina de la ciencia; eso es otro asunto (FWS IV, 374).

Ahora bien, esta diferenciación a partir de la opinión corriente o dominante marca la tarea problemática de la WL como filosofía bien entendida. Pues, su tarea es comprender el saber (Das Wissen) no como algo producido por un objeto exterior, ni como el contenido de una doctrina ya hecha, lo que representaría una verdad dogmática, sino como algo que se forma en nosotros por medio de nuestra reflexión sobre nuestro saber, es decir sobre los conceptos y las categorías que utilizamos para formar nuestro juicio. Algo que debe ser reconstituido en el presente por medio de su ejercicio. Como mencionamos antes la WL se plantea aclarar de forma incesante lo que queda "invisible" a la conciencia natural. Así su trabajo específico consiste en visualizar los actos que producen todo saber en nosotros. Este esclarecimiento está destinado a implementar una potenciación de nuestra forma de actuar en el mundo. Una potenciación a la que Fichte llama sabiduría (Weisheit): "La doctrina de la ciencia 
debería considerarse como sabiduría, guía del vivir y del actuar" (FWS IV, 389). Eso puede ser considerado el efecto, o el objetivo último de la WL ${ }^{22}$.

\section{Las dificultades de la Doctrina de la ciencia}

En 1811 la comprensión del punto mencionado tiene que ver con una de las dificultades del desarrollo de la WL es decir de entenderla como una filosofía entre otras. Fichte afirma que siempre se ha "esforzado" para abrir a la comprensión de la intuición fundamental de la WL; que su ambición ha sido abrir un "camino orgánico" para alcanzarlo. Y que sería por esta razón que él la expone cada vez de forma nueva. Con sus palabras: "Mi tesón incesante tuvo como objeto allanar este camino orgánico para la exposición. Y porque pretendo tal fin, en cada nueva exposición presento la $\mathrm{D}$ [octrina] de la C[ciencia] de una forma diferente" (DC 1811, 64).

A esta altura cabe recordar que en la época de Jena Fichte expresaba la diferenciación que la filosofía exige y produce justamente por medio de la categoría del esfuerzo (Streben) cuyo significado de 'tensión' se aproxima en los cursos berlineses a las categorías del debe (Soll), o del deber ser (seyn sollen) y se ancla en una pulsión (Trieb). Y como suele pasar a menudo en los manuscritos de los cursos berlineses, Fichte se sirve de expresiones forjadas en Jena para explicar a sus estudiantes su manera de filosofar. Eso tiene que ver básicamente con dos razones pragmáticas. Fichte se refiere a las obras que él había publicado en Jena y que indica en los anuncios de sus cursos en Berlín. Se trata de las obras que su audiencia conoce (directa o indirectamente) en la medida que esos textos fueron el objeto de la recepción pública de su filosofía.

Ahora bien, hemos visto que, en las clases introductoras, Fichte intenta predisponer a sus oyentes a la inteligencia de la WL. Él presenta también las dificultades concretas con las cuales ellos tendrán que enfrentarse. Sus observaciones sobre este punto nos permiten analizar la WL a partir de su ejercicio efectivo, y evidenciar su dimensión pedagógica concreta en el marco de la 'exhortación'. Fichte explica cómo logró la intuición de la WL, o sea los pasos básicos por los cuales él mismo alcanzó su propia visión. Bajo esta perspectiva, ofrece un ejemplo (Vorbild). Al mismo tiempo el acto de filosofar consiste en un trabajo que cada uno tiene que cumplir por su cuenta a partir de una decisión de cuestionar el formarse del saber cómo tal en la conciencia.

A partir de esta observación podemos entender la preocupación fundamental de Fichte durante su enseñanza en la Universidad de Berlín. Fichte no buscaba encontrar una forma "perfecta" o definitiva para la WL (lo que sí había sido su intento tras dejar Jena y hasta por lo menos 1804), sino que quería facilitar a sus estudiantes la posibilidad de formarla en sí mismos. Si eso es cierto, habría que tomarlo en cuenta en la manera de enfrentarse a los manuscritos de sus clases berlinesas ${ }^{23}$. No se trata de leer estos apuntes como si Fichte hubiese pensado en publicarlos para finos filólogos, sino justamente como un laboratorio de intentos concretos para impulsar esta visión que Fichte llama de WL. En este laboratorio Fichte utiliza imágenes del lenguaje común y referencias conocidas por su público como base para exhortar a la formación de una mirada diferente en la cual consistiría la filosofía como ejercicio del pensamiento crítico.

Así, la esencia de la WL es la reproducción creadora de un conjunto de pensamientos (Denkzusammenhang). Es la razón por la cual Fichte designa como "Sapere aude" el principio de la mnemónica en los Hechos de la consciencia. Su ejercicio consiste en una 
apropiación singular y reproducción creadora de la interrogación transcendental sobre el saber. "Y más la consciencia será clara y libre, más ella se fortalecerá, más la memoria será amplia y reactiva" (GA II,12, 51). En 1798 Fichte sostiene que "la facultad de recordar depende de la libertad, y en consecuencia del ejercicio. $Y$ aquello que hace posible ese recuerdo es la ley de la asociación de ideas" (SisEt, 370). Por eso Fichte sustenta en la Doctrina de la ciencia de 1811 que el trabajo de la filosofía es "unificar luego de modo orgánico en una visión de conjunto [...] Mostrarlo claramente en la conexión en que se pueda; pero luego, al menos, mostrar la auténtica conexión en la que debería hacerlo aclarado" (DC 1811, 64). En breve, lo que cuenta es esta visión del conjunto (Einsicht).

Fichte avisa a sus oyentes que "seguir este proceso estrictamente orgánico en una exposición efectiva tiene ahora sus dificultades" (DC 1811, 64). Por eso, exige un esfuerzo que él expresa justamente con la divisa de la Ilustración. Es en este sentido que el lema aparece en la Lógica transcendental. "Analizar con calma y sapere aude sin prejuicios" (Ruhig analysiren. u. unbefangen sapere aude) (GA II,14, 145). Este esfuerzo tiene que ver entonces con el problema de la comunicación de la visión (Einsicht) de la WL a un público determinado. Pues, "se trata de distinguir lo que la conciencia natural no distingue, siendo que el hombre tiene una tendencia natural a no distinguir. [Hay aquí] por consiguiente un oponerse y un liberarse: y de hecho una criatura nueva" (DC 1811, 63).

En el prólogo de 1811 Fichte habla de dos dificultades principales (Hauptschwierigkeiten). La primera tiene que ver con la comprensión de la filosofía como una clasificación de las filosofías y la segunda con la acción del pensamiento o sentido dogmático (dogmatischen Sinn). La primera dificultad tiene que ver con un malentendido respecto al ejercicio de la filosofía. La filosofía no es un método para catalogar visiones que se pretenden filosóficas. No se trata de catalogar las tesis de otros desde un punto de vista exterior a ellas. La filosofía como WL rechaza toda posición de neutralidad hermenéutica. Así, el ejercicio del pensamiento critico exige un compromiso de naturaleza moral.

Bajo esta óptica, podemos entender la WL como ejercicio de la Ilustración, según la definición que Kant formula en 1984, o sea "el abandono por parte del hombre de una minoría de edad cuyo responsable es él mismo. Esta minoría de edad significa la incapacidad para servirse de su entendimiento sin verse guiado por algún otro" ( $A A$ VIII, 35) ${ }^{24}$. El 'sentido dogmático' inscribe la "pereza" (Faulheit) en la práctica teórica ${ }^{25}$. Se trata de la tendencia natural de la conciencia a confundir o transformar el objeto del conocimiento (el objeto como "imagen de la imagen") en el objeto real, o sea una "cosa". Lo que Fichte expresaba en Jena con la oposición entre espíritu y letra. Si la WL in especie analiza los actos de la actividad del pensamiento que están implicado en la constitución o formación de todo saber en la conciencia, todo objeto determinado del conocimiento se queda todavía como híbrido (combinación de fe y entendimiento). La particularidad del sentido dogmático es su trato espontaneo de imponerse en la conciencia. Fichte lo llama también "inclinación natural" (natürlicher Hang) o "contra pulsión" (Gegen-Trieb). Podemos entenderla como la modalidad espontanea para la constitución o la percepción de sí misma y sus contenidos concretos por parte de la conciencia natural bajo la forma 'sujeto-objeto' como si estos términos fuesen preconstituidos antes del surgimiento del pensamiento. Esta tendencia espontánea de la conciencia natural - que podríamos entender como una remoción de los actos implicados en nuestra percepción del objeto del conocimiento - constituye un 
movimiento que se opone al esclarecimiento científico que marca y define la WL como esfuerzo de pensar por sí. De esta manera, las consideraciones preliminares y todo curso de introducción, lejos de cumplir una tarea propedéutica, tratan de hecho con un problema interno al desenvolvimiento del pensamiento crítico y que se presenta de manera permanente. Pero, además, el saber de la conciencia natural se presenta como una condición de la posibilidad del discurso filosófico. Así, la comprensión dogmática de la letra por parte de la conciencia natural, sus malentendidos, forman parte de sus efectos inevitables, que hay que tomar en cuenta de forma incesante tanto en su desarrollo como en su interpretación. Por supuesto a la altura de los prolegómenos se podría pensar enfrentarnos a los productos del pensamiento común, las posiciones dogmáticas o todo prejuicio sobre la WL que se ha producido históricamente. Estos productos están destinados a desaparecer como ilusorios ya que vamos a liberarnos una vez por todas de ellos al momento de plantear el desarrollo de la WL. O sea, se podría pensar que el punto de vista filosófico borra para siempre el punto de vista natural ${ }^{26}$. Fichte nos plantea, sin embargo, algo diferente. Si entendemos la conciencia natural como un estadio que hay que borrar por completo, esta comprensión significaría comprender la WL meramente como un hecho histórico, perdiendo su dimensión creadora y desviando nuestra atención de lo que está en juego a esta altura. Pues la tarea básica de la filosofía consiste en producir y practicar la visión clara (Klare Einsicht). El punto crucial es que cuando ponemos en práctica la WL, cuando cuestionamos nuestros conceptos, criterios de juicios, opiniones bajo una perspectiva genética o transcendental en cada momento, en cada posición que formulamos o proponemos, todo lo que nos figuramos puede reconstituirse de nuevo como letra, posición del pensamiento común, doctrina dogmática, concepto inadecuado de la WL, visión del mundo distinta bajo la forma de 'sujeto-objeto' constituido de antemano. Si el saber sigue reglas en su formación, estas mismas reglas se conocen solamente a partir de una apropiación singular por parte del sujeto que escoge de reflexionar sobre el acto que produce el conocimiento y sobre sus efectos en la consciencia que él tiene de sí mismo y de su actitud hacia el mundo. Al revés, si perdemos la consciencia de esta dimensión practica y creadora, volvemos a operar según la modalidad de constitución del saber que caracteriza al pensamiento dogmático. Con lo cual toda figura o esquema de la WL no constituye en sí mismo un criterio formal del saber, una garantía de su cientificidad válida para siempre y que el éxito de la WL depende en última instancia del "arte del profesor y de la capacidad de intuición del estudiante" (GA 2,12, 155) Esto implica, además, que, desarrollándose, la WL no pone solamente el punto de vista científico, sino que ella encuentra, pone y dispone en su mirada también todo otro punto de vista, por ejemplo, en la distinción entre los puntos de vista del realismo y del idealismo con sus distintos grados de articulación, transformándose en el punto de vista que les distingue y que los sostiene. Con otras palabras, para afirmarse como punto de vista científico en su análisis, la WL se realiza como tal, si se forma como su línea de demarcación, interpelando al cumplimiento efectivo de la comunidad que interpela por medio de su discurso. Su exposición como letra de los manuscritos constituye por lo tanto apenas un ejemplo, un aspecto de un proceso del cual nosotros podemos solamente analizar la imagen, la letra ex post. Este aspecto se relaciona con la verdad solamente si se comprende en su singularidad, y resulta efímero cuando se entienda como doctrina cuya letra sería valida de por sí y para siempre. Indica por lo tanto básicamente un ejercicio. 


\section{Conclusión}

Exhortándonos a saber, los Prolegómenos nos invitan entonces a la liberación de los efectos del funcionamiento subconsciente, irreflexivo o factual de la conciencia natural, y nos anuncian una nueva manera de ver que deriva de esta nueva actitud de pensamiento. A partir de esta perspectiva la tarea de la filosofía como ejercicio la WL es de luchar contra todo malentendido constituido de antemano bajo la forma de convencimiento (o resistencia subjetiva), que pueda presentarse como posición de un sujeto, como concepto de un individuo ' $x$ ' tenga de la filosofía (GA II,12, 150). Al mismo tiempo la filosofía como WL o supone y parte factualmente de este saber común, no aclarado, ni reflexionado hasta el final, que constituye el objeto sobre el cual inicia su reflexión por medio de la abstracción y la interrupción de la serie real de representaciones. Pero, además, encuentra este saber común en todo momento de su desarrollo como cristalización del pensamiento que se vuelve letra que invisibiliza su génesis, el movimiento del espíritu, o sea el formar, el poner que constituye su verdadero objeto.

La exposición efectiva tiene sus dificultades para seguir de forma rigurosa el camino orgánico de la WL como ejercicio del pensamiento crítico. Pues, como Kant sustentaba: "resulta difícil para cualquier individuo el zafarse de una minoría de edad que casi se ha convertido en algo connatural" (AA VIII, 36) ${ }^{27}$. Como hemos visto, para Fichte, la dificultad de la comprensión de la WL depende del hecho que

algunos puntos concretos yacen tan lejos de la consideración ordinaria y contradicen tanto la propensión natural, que es una dificultad particular expresarlos inmediatamente de mondo simbólico en el lenguaje habitual; por eso es aconsejable enlazar la lección con otra más fácil, y sólo desde ésta proyectar a lo más difícil la luz generada allí (servirse de algún modo de estas [intelecciones más sencillas] como guías de ayuda)" (DC 1811, 64).

El ejercicio efectivo de la filosofía parte del 'símbolo' compartido por la comunidad de oyentes. Como Fichte explica en el Sistema de Ética: "el símbolo debe estar acomodado a todos, incluso a los incultos, en su concepto se encuentra el que no consiste en proposiciones abstractas, sino en representaciones sensibles del mismo. La representación sensible es simplemente la envoltura; el concepto es lo propiamente simbólico" (SisEt, 273). El trabajo del filósofo es comprometerse con las opiniones corrientes y aprender el arte para impulsar visiones más claras o ilustradas, formar una inteligencia superior del mundo por parte de su comunidad. Como Fichte destaca en 1811:

cuando se le revela al hombre el [sentido] superior, no surge ningún nuevo lenguaje, el antiguo tiene que emplearse simbólicamente, es decir, mediante una imagen del sentido externo se designa por analogía, una imagen que surge del interno. Este empleo simbólico no tiene otros limites que los que tiene el pensamiento" (DC 1811, p. 63).

La exposición es necesariamente por lo tanto siempre simbólica "porque sin acuerdo sobre algo cualquiera no era posible ninguna comunicación recíproca”. O sea, la exposición es una comunicación que tiene como punto de partida las convicciones corrientes. Lo que caracteriza el símbolo es la convicción que "hay en general algo suprasensible y elevado por encima de toda naturaleza" (SisEt, 273).

Los prolegómenos de la WL constituyen una exhortación al público presente para predisponer a cada oyente para efectuar un tipo particular de ejercicio. La exposición de la WL presupone siempre una determinada comunidad de escucha. Los 
prolegómenos representan por lo tanto una exhortación para instituir esta comunidad por medio de la definición del objetivo común. Este objetivo consiste en cuestionar radicalmente el saber. Según Fichte, la exhortación (Aufförderung) es el fundamento de toda relación entre seres racionales, tanto políticas como pedagógicas. En el Fundamento del derecho natural la exhortación explica la autoconsciencia y la autodeterminación del yo en cuanto ser libre y moral.

Pero el mismo no se concibe y no puede concebirse salvo como una mera exhortación del sujeto para actuar. De ahí que tan cierto como el sujeto comprende el mismo, tan cierto tiene el concepto de su propia libertad y espontaneidad, y en verdad como una dada desde fuera. Él recibe el concepto de su actividad causal libre no como algo que es en el momento presente, puesto que sería una verdadera contradicción, sino como algo que debe ser en el futuro (FDN, 127).

En el Sistema de ética, Fichte aclara que la autodeterminación depende de un concepto bajo la forma de una exhortación a la cual el sujeto se da a sí mismo como libre (SisEt, 256). Ahora bien, en el prólogo de la WL de 1811 Fichte exhorta a sus auditores a osar pensar libremente y salir de la protección 'confortable' de las autoridades. En este sentido él habla de una nueva mirada, de un esfuerzo y de un compromiso ético. Nuestra época prova la convicción de Kant según la cual para el hombre "es tan cómodo ser menor de edad" (AA VIII, 35) ${ }^{28}$. Según Fichte, "la inercia, que se reproduce a sí misma por una larga costumbre y pronto se convierte en una total incapacidad para el bien, es el verdadero mal radical innato que se halla en la naturaleza humana misma, el cual puede muy bien explicarse a partir de ella" (SistEt, 242). Él se compromete contra esta actitud. La exhortación: '! Sapere aude!' expresa un destino del hombre como sujeto ético. Así, la verdadera filosofía como pensamiento crítico in actu se resume y realiza en una actitud ético-crítica constante. Por esta razón: "e 1 ejercicio y la atención, la vigilancia sobre nosotros mismos, han de perdurar siempre y nadie está seguro ni un momento de su moralidad sin ese continuo esfuerzo" ( SisEt. 235).

\section{NOTAS}

1. Fichte define como 'genético' el conocimiento que es consciente de su proceso de formación (FWS IV, 379).

2. Como destacan Gabriel y Žižek: "Post-Kantian Idealists share Kant's preoccupation with transcendental illusion but argue that illusion (appearance) is constitutive of the truth (being)" (Gabriel \& Žižek, 2009, p. 1)

3. "Pero aquel no-reflexionar sobre el pensamiento ahí donde se piensa, aun cuando, caso de que el pensamiento dado sea conforme a las leyes, tampoco surge un error objetivo, es en cambio fallido: por un lado, porque entonces la verdad objetiva es alumbrada exclusivamente por el oscuro instinto racional, pero no por un conocimiento libre y claro; por otro lado, porque mediante este modo podría generarse un error. Es decir, para el pensamiento se borra toda distinción entre verdad y error (Critica de la razón pura de Kant)" (FICHTE, J.G., (1999), Doctrina de la ciencia 1811. Edición de Alberto Ciria. Madrid, Alkal [=DC 1811)], 60). 
4. En un paso celebre de la introducción al Fundamento del derecho natural según los principios de la Doctrina de la ciencia, Fichte explica que "Pero puesto que él ya no encuentra este Yo agente originariamente en la conciencia empírica, lo pone, por el único acto de arbitrio que le está permitido en su punto de partida, (y que es la libre decisión misma de querer filosofar) y desde este punto lo hace continuar actuando ante de sus ojos según sus leyes propias, perfectamente conocidas por el filósofo" (FDN, 106).

5. Pues, el mismo Kant colocaba el "epicentro de la ilustración [...] en cuestiones religiosas" porque consideraba el oficio de tutores en este ámbito como el "más nocivo e infame" (AA VIII, 41; traducción en castellano: KANT, I. (2013), “Contestación a la pregunta: ¿Qué es la Ilustración? ” en: KANT, I. ¿Qué es la Ilustración? Y otros escritos de ética, política y filosofía de la historia. Edición de Roberto R. Aramayo. Madrid, Alianza, 2013, 92).

6. Como explica de forma magistral Günter Zöller: "En una deposición deliberada de la cultura escrita en la actividad

filosófica, Fichte desiste de la obra (Werk) en favor del efecto (Wirkung) y en lugar del desarrollo progresivo de múltiples contenidos prioriza la repetición variada de pocos temas y tesis fundamentales; y esto siempre con nuevos ensayos en el marco de un procedimiento elegido de manera premeditada, por medio del cual se deben desafiar, deshacer y reemplazar los modos de pensar establecidos" (ZÖLLER, G., (2015), Leer a Fichte, Barcelona, Herder editorial, 23).

7. BERTINETTO, A., (2009), "Faktum und Genesis in der Wissenschaftslehre von 1804/II", in GODDARD, J.-C. \& SCHNELL, A (eds), L'Être et le phénomène. Sein und Erscheinung, Paris, Vrin, 85-96.

8. Cf. BINKELMANN, C., (2009), "Der Weg zum absoluten Wissen. Die Funktion der Prolegomena in der Wissenschaftslehre von 1804/II”, in: GODDARD \& SCHNELL, 2009, 97-108.

9. Sobre este uso veáse: RAMETTA, G, (2012), Fichte, Roma, Carrocci, 43.

10. Cf. D’ALFONSO, M. (2005), Vom Wissen zu Weisheit. Fichtes Wissenschaftslehre von 1811. Amsterdam/New York, Rodopi, 66.

11. "Die Uebereinstimmung über die Einsicht nennt man das Symbol: und die der Voraussetzung nach durch dieselbe gefasste Gemeine, (diejenige, die an das Symbol glauben) Gemeine der Gläubigen" (SL 1812, 383).

12. Sobre este punto véanse también: PHILONENKO, A., (1988), Théorie et Praxis dans la pensée morale et politique de Kant et Fichte en 1793, Vrin, Paris, 80-83.

13. Cf. KANT, I. 2013, 91.

14. "[...] das sich lebendig ausgesprochen in todte Buchstaben verwandelte" (FimG 4, 288].

15. RADRIZZANI, I. (2006), “La Doctrine de la Science et l'Aufklärung”, in: Revue de métaphysique et de morale, 49, n 1, 127-142, en part. 133.

16. ROUSSEAU, J-J., "Discours sur les Sciences et sur les Arts", in: đuvres complètes (sous la direction de B. Gagnebin e M.Raymond), Gallimard, Paris, 1959-1995, V. III, p. 131.

17. GA I,6 59.

18. FUCHS, E., (2004), "Fichte und die Berliner Aufklärung”, in: DE PASCALE u.a. Fichte und die Aufklärung, Hildesheim, Zürich, New York Olms, 2004, 53-68.

19. ZÖLLER, G., (2004), "Kant, Fichte und die Aufklärung” in DE PASCALE, 2004, 35-52, en part. p. 46.

20. Cf. AA VIII, 41.

21. ROUSSEAU, J-J., "Du Contrat social", in : Euvres Complètes, (sous la direction de B. Gagnebin e M. Raymond), Gallimard, Paris, 1959-1995, V. III, 394.

22. Véanse: RAMETTA, G., (1995), Le strutture speculative della dottrina della scienza, Genova, Pantograf, 151-163.

23. Cf. RAMPAZZO BAZZAN, M. (2016), "Sobre la huella de Kant en la doctrina del derecho berlinesa de Fichte”, in: Estudos Kantianos, Marília, v. 4, n. 1, Jan./Jun., 2016, 83-104.

24. KANT, I., 2013, 83.

25. "El hombre es por naturaleza perezoso, dice Kant muy correctamente" (SistEt, 242). 
26. Aquí retomo aspectos del estudio : RAMPAZZO BAZZAN (2015), La doctrine de la science comme pratique réflexive de production d'image, in Fichte-Studien 42, 2015, 195-215.

27. KANT, I., 2013, 84

28. KANT, I., 2013, 83.

\section{RESÚMENES}

This paper aims at studying how Fichte appropriates Kantian definition of Enlightenment during his teaching at the University of Berlin (1810-1814). This appropriation is pointed out by three significant recurrences of the motto "Sapere aude!" in his lessons of Doctrine of Knowledge (1811), Facts of consciousness (1810/11) and Transcendental Logic (1812). I analyze these recurrences to understand, on the one hand, what kind of practice Fichte recommended his students for improvement, and on the other one, the perspective anchored in the present that grounded his conception of human history in his Doctrine of State. my goal is to characterize his Doctrine of Knowledge as a practice of critical though in actu.

ÍNDICE

Keywords: Doctrine of Knowledge, Enlightenment, Symbol, Fichte, Kant

\section{AUTOR}

\section{MARCO RAMPAZZO BAZZAN}

Universidade Federal do Espírito Santo (UFES) 